\title{
History as inspiration
}

\author{
Dr. Vu Thi Hanh
}

History is written in textbooks but is indubitably remembered through cultural artifacts and architecture. This is particularly the case when one thinks of Hanoi, where its thousands of years of ancient history can be found in the old citadels and more than half a century of French colonialism can be glimpsed in the houses of the Old Quarter. Many of these structures have survived the brutality of wars and now feed into nostalgia for the French aesthetic.

Yet, in what way can we come to gain greater insight into a cultural space where there is an interconnection between religion, house designs, and forms of feeling? One can find an answer to this question in new scientific research entitled “Cultural Revolution in Vietnam's Early 20th century: A Bayesian Networks Analysis of Hanoi Franco-Chinese House Designs" published in Elsevier's Social Sciences and Humanities Open journal.

The study is the first of its kind to systematically break down elements of house façades in Hanoi's Old Quarter and examine them against the rich cultural-historical continuity of the city and the country as a whole. These are the very old houses that today live on in the oil paintings of Vietnamese artist Bui Xuan Phai (1920-1988), whose name intrinsically conjures up images of "Phai streets". The authors, allegedly inspired by Bui Xuan Phai's paintings and historical remnants in the capital, make a brave attempt to statistically analyze and remember the Franco-Chinese architecture in Hanoi's historic streets.

The old houses, many of which have undergone urbanization and commercialization, are documented through 248 photos taken by one of the co-authors, the Vietnamese artist Bui Quang Khiem, in the ten years from 2007 to 2018. This approach alone speaks volumes to the meticulous preparation and patience in conducting research on cultural history.

It comes as an interesting surprise that the type of research data in this study goes beyond such usual methods as observational, experimental, simulation, and derived. In fact, researchers can make data out of what they observe. In other words, the authors see with their own eyes the actual house façade as well as the photos of Hanoi Old Quarter house façades in order to encrypt these images and their elements into data.

Given this approach, the data are inevitably subjective - the authors give their evaluation of the house façade based on their own feelings, knowledge, and judgments about Hanoi's ancient architecture. The method to generate input data from the study is exceptional, from seeing the photos (sense) then receiving information about the architectural decoration of the façade of the old houses (perception) to feeling the 
spirit of old house images (feeling). Feelings of the traditional, feelings of modern and, feelings of cultural evolution add extra spatial dimensions to our big three-dimensional space that makes modern and old Hanoi discernible. Since feelings may be colored by personal experience, belief, or even memories, the use of quantitative and qualitative data can improve storytelling about Vietnam's culturalarchitectural evolution in a more subtle way.

While the dataset in this study is not large and has its limitations, it stands out in a unique manner - the 72 data lines were recorded through a series of photos of Hanoi's old houses characterized by Vietnam's cultural evolution in the early 20th century, and hence, the value of the information is constant regardless of time or space.

The use of Bayesian networks analysis allows the construction of independent and dependent variables that capture the façade decoration of the old houses as close as possible to the religious culture of Vietnam. For example, regarding Buddhist-inspired decorations in façade designs, lotus flowers symbolize spiritual enlightenment and rebirth. Taoistinspired patterns are represented by a cloud or an octagonal "fengshui bagua" mirror, while Chinese characters or paper rolls decorated on the façades of Hanoi's old houses are symbols of Confucianism.

Among its notable findings, the authors reveal the high probability of hybrid value when there is a weak presence of Buddhist-inspired decorative symbols. Additionally, when the decoration of a façade is hybrid, the probability of the cultural evolution happening is at its highest. Understanding these changes requires one to dig deeper into the past, to grasp the historical contexts against which such changes were brought about. And this is why scientific studies of this kind are enormously valuable, even as one may debate its subjectivity and model construction. The knowledge of culture, religion, architectural designs, and scientific explanation are all employed to confirm traces of cultural evolution in the 20th century of Vietnam through the Franco-Chinese style old houses of Hanoi.

Cultural evolution is not easy to study, but this study proves that it is not impossible either. A political empire may not last long; an economic policy may need to be revised; human needs may change, and our names will be forgotten. The study reminds us of the long-lasting status of the cultural values of Hanoi's Old Quarter. 


\section{References}

[1] Vuong QH, et al. (2018). Cultural additivity: behavioural insights from the interaction of Confucianism, Buddhism and Taoism in folktales. Palgrave Communications, 4(1), 143.

[2] Vuong QH, et al. (2019). Cultural evolution in Vietnam's early 20th century: A Bayesian networks analysis of Hanoi Franco-Chinese house designs. Social Sciences \& Humanities Open, 1(1), 100001.

[3] Vuong QH, \& Tran TD. (2009). The cultural dimensions of the Vietnamese private entrepreneurship. The IUP J ournal of Entrepreneurship and Development, 6(3), 54-78. 